\title{
Cryoprotective effects of some amides on rabbit spermatozoa
}

\author{
A. Hanada and H. Nagase \\ National Institute of Animal Industry, Tsukuba Nohrindanchi, P.O. Box 5, Ibaraki 305, Japan
}

\begin{abstract}
Summary. Semen was diluted 1:9 with egg yolk-citrate medium containing 0.31$3 \cdot 1$ M (final concentration) formamide, butyramide, acetamide, propionamide, dimethylformamide, lactamide, malomide, ethylene glycol, trimethylene glycol, dimethylsulphoxide (DMSO) or glycerol. After $30 \mathrm{~min}$ incubation at $20^{\circ} \mathrm{C}$, sperm motility was superior in hypertonic solutions of acetamide, lactamide, dimethylsulphoxide, trimethylene glycol and ethylene glycol. Some of these compounds were added to semen diluted $1: 2$ in an isotonic egg-yolk-glucoselactose-raffinose solution and frozen by the pellet method. Relatively good survival of motility was obtained in 1.0 M-DMSO, -lactamide or -acetamide. Dimethylformamide $(0.5 \mathrm{M})$, ethylene glycol $(0.5-1.5 \mathrm{M})$, trimethylene glycol $(1.5 \mathrm{M})$ and propionamide $(0.75 \mathrm{M})$ also gave some protection. Insemination of does with semen frozen and thawed with $1.0 \mathrm{M}$-DMSO, -lactamide or -acetamide gave fertilization rates of $68-88 \%$, and $84 \%(38 / 45)$ of does gave birth to an average of $5 \cdot 3$ young.
\end{abstract}

\section{Introduction}

In studies on the deep freezing of semen, several factors make rabbit spermatozoa of particular interest in comparison to those of some other species. Rabbit spermatozoa are less sensitive to rapid cooling from 30 to $0^{\circ} \mathrm{C}$ than are bull, dog or ram spermatozoa (Wales \& White, 1959), but they are very sensitive to damage by hypertonic solutions (Emmens, 1948). Rabbit spermatozoa also appear to be less permeable to glycerol (Nagase \& Tomizuka, 1969) and a sudden rise of glycerol concentration in the diluent leads to loss of motility (Smith \& Polge, 1950). Early attempts to achieve fertilization with rabbit semen frozen and thawed in the presence of glycerol were relatively unsuccessful, but better results were achieved using ethylene glycol (Fox \& Burdick, 1963) or dimethylsulphoxide (Sawada \& Chang, 1964) as cryoprotective agents. High kindling rates with frozen rabbit semen have been documented and observations have been made on several factors relating to rabbit semen freezing, such as sperm numbers for inseminations (Andrieu \& Courot, 1976), acrosome morphology (Weitze, Hellemann \& Krause, 1976; Hellemann, 1977), storage periods (O'Shea \& Wales, 1969; Maurer, Stranzinger \& Paufler, 1976), sperm transport in the female reproductive tract (Murdoch \& O'Shea, 1973) and freezing procedures (Stranzinger, Maurer \& Paufler, 1971; Weitz et al., 1976). However, no cryoprotective agents other than glycerol, dimethylsulphoxide and ethylene glycol have been examined for the low temperature preservation of rabbit semen. We have previously demonstrated that formamide, acetamide and lactamide provided good protection to bull, stallion and boar (except formamide) spermatozoa during pellet freezing (Nagase, Tomizuka, Hanada, Hosoda \& Morimoto, 1972; Tomizuka, Hanada, Morimoto \& Nagase, 1972) and so we investigated the effectiveness of these and some other neutral solutes for the preservation of rabbit spermatozoa. 


\section{Materials and Methods}

\section{Semen}

Semen was collected by means of an artificial vagina from New Zealand White bucks aged 1-3 years during November to April. Only ejaculates of good initial motility were used and these were pooled for each experiment.

\section{Diluents and cryoprotective agents}

Eleven substances were investigated for their effect on sperm motility and as protective agents during freezing and thawing. These were formamide, acetamide, lactamide, propionamide, dimethylformamide, butyramide, malomide, ethylene gylcol, trimethylene glycol, dimethylsulphoxide and glycerol. For incubation trials at $20^{\circ} \mathrm{C}$ the substances were dissolved in a solution of $3 \%(\mathrm{w} / \mathrm{v})$ sodium citrate plus $20 \%(\mathrm{v} / \mathrm{v})$ egg yolk.

For freezing and thawing trials and for semen used for insemination the substances were dissolved in a solution containing $125 \mathrm{~mm}$-glucose, $111 \mathrm{~mm}$-lactose, $91 \mathrm{~mm}$-raffinose and $20 \%$ $(\mathrm{v} / \mathrm{v}) \mathrm{egg}$ yolk. These diluents were centrifuged at $5500 \mathrm{~g}$ for $15 \mathrm{~min}$ to remove the insoluble fractions of egg yolk which made it difficult to evaluate sperm motility.

\section{Sperm survival at $20^{\circ} \mathrm{C}$}

Samples of $2 \mathrm{ml}$ diluted semen were incubated at $20^{\circ} \mathrm{C}$ for $30 \mathrm{~min}$ and the proportion of motile spermatozoa was determined by visual assessment $(\times 400)$ under a coverslip on a warm stage kept at $40^{\circ} \mathrm{C}$.

\section{Freezing test}

The diluted semen was cooled to $5^{\circ} \mathrm{C}$ over a period of $1 \mathrm{~h}$ and then frozen as pellets $(0.2 \mathrm{ml})$ on solid $\mathrm{CO}_{2}$. The pellets were left for $1 \mathrm{~h}$ on solid $\mathrm{CO}_{2}$ before thawing by tipping them onto a metal plate at $40^{\circ} \mathrm{C}$. Motility assessments were made on samples with or without the addition of a thawing diluent consisting of $180 \mathrm{~mm}$-potassium bromide, $90 \mathrm{~mm}$-sodium citrate and 30 mM-glucose. Two experiments on the fertilizing capacity of frozen-thawed semen were carried out. In the first, samples from pooled ejaculates were diluted in media containing $1 \mathrm{M}^{-}$ dimethylsulphoxide, -acetamide or -lactamide, $0.5 \mathrm{M}$-dimethylformamide. After freezing on solid $\mathrm{CO}_{2}$, the pellets were thawed in a metal tube held in a water bath at $40^{\circ} \mathrm{C}$ just before insemination. New Zealand White females used in this experiment were 2-3 years of age and had been and remained caged individually. Vulval colour and swelling were checked daily to detect oestrus and the animals were then inseminated by means of a glass pipette $5 \mathrm{~h}$ after intravenous injection of 20 rabbit units of hCG (Teikoku Zoki Co.). Three pellets $(0.6 \mathrm{ml})$ containing a total of $115.8 \times 10^{6}$ spermatozoa were inseminated per doe and the number of motile spermatozoa ranged from about $40 \times 10^{6}$ (dimethylformamide) to $52 \times 10^{6}$ (the other substances tested).

The does were laparotomized $48 \mathrm{~h}$ after artificial insemination and eggs were recovered from the oviduct by flushing with saline $(9 \mathrm{~g} \mathrm{NaCl} / \mathrm{l})$. The eggs were fixed as whole mounts in $25 \%$ acetic alcohol, stained with lacmoid and the proportion showing normal cleavage and development was assessed. In the second experiment 45 semen samples from 42 bucks were frozen individually in $1 \mathrm{M}$-dimethylsulphoxide, -acetamide of -lactamide. After freezing on solid $\mathrm{CO}_{2}$, the pellets were stored in liquid nitrogen for $1-14$ days and 3 pellets $(0.6 \mathrm{ml})$ per doe were used for inseminations. All samples showed more than $35 \%$ motile spermatozoa after thawing and the number of motile spermatozoa per insemination varied from $8.6 \times 10^{6}$ to $13 \times 10^{6}$. The does were allowed to go to term and the litter size was checked at parturition 29-32 days after insemination. 
Sperm survival at $20^{\circ} \mathrm{C}$

\section{Results}

Sperm motility in diluents containing increasing concentrations of the added solute is shown in Table 1. There was little difference in motility when the solute was added at isotonic concentrations $(0.31 \mathrm{M})$, except for butyramide in which motility was greatly reduced. Sperm motility was maintained at a fairly constant level in solutions containing dimethylsulphoxide and trimethylene glycol up to 7 times the isotonic strength $(2 \cdot 17 \mathrm{M})$ and in solute concentrations of acetamide, lactamide and ethylene glycol up to 5 times the isotonic strength $(1.55 \mathrm{M})$. In the other media the motility dropped precipitously with increasing concentration of the additive. The $\mathrm{pH}$ values of each diluent varied to some extent depending on the solutes in the basic medium. The overall range of the values was between $6.2(3.1 \mathrm{M}$-propionamide) and $7.6(3.1$ M-dimethylsulphoxide). Therefore the $\mathrm{pH}$ effect of the diluents on sperm motility might be considered to be negligible.

Table 1. Effects of various cryoprotectants in an egg yolk-citrate diluent on the motility of rabbit spermatozoa after incubation at $20^{\circ} \mathrm{C}$ for $30 \mathrm{~min}$

\begin{tabular}{llllll}
\hline & \multicolumn{5}{c}{ Conc. (M) } \\
\cline { 2 - 5 } \multicolumn{1}{c}{ Cryoprotectant } & $0 \cdot 31$ & 0.93 & $1 \cdot 55$ & $2 \cdot 17$ & $3 \cdot 10$ \\
\hline Dimethylsulphoxide & $62 \pm 3$ & $63 \pm 4$ & $61 \pm 4$ & $60 \pm 3$ & $38 \pm 9^{*}$ \\
Lactamide & $61 \pm 3$ & $62 \pm 4$ & $57 \pm 4$ & $51 \pm 6$ & $35 \pm 7^{* *}$ \\
Acetamide & $60 \pm 3$ & $61 \pm 4$ & $54 \pm 4$ & $45 \pm 3^{*}$ & $30 \pm 2^{*}$ \\
Trimethylene glycol & $50 \pm 3$ & $52 \pm 3$ & $54 \pm 4$ & $54 \pm 4$ & $52 \pm 3$ \\
Ethylene glycol & $48 \pm 3$ & $50 \pm 2$ & $50 \pm 4$ & $39 \pm 10$ & $27 \pm 11$ \\
Dimethylformamide & $63 \pm 1$ & $55 \pm 4$ & $33 \pm 10^{*}$ & $18 \pm 5^{* *}$ & 0 \\
Malomide & $61 \pm 2$ & $33 \pm 9^{* *}$ & $7 \pm 5^{* *}$ & $5 \pm 3^{* *}$ & 0 \\
Formamide & $53 \pm 5$ & $39 \pm 2^{*}$ & $16 \pm 6^{* *}$ & $4 \pm 2^{* *}$ & 0 \\
Propionamide & $44 \pm 6$ & $46 \pm 7$ & $19 \pm 11$ & $6 \pm 6^{* *}$ & 0 \\
Glycerol & $47 \pm 1$ & $23 \pm 5^{* *}$ & $7 \pm 6^{* *}$ & $3 \pm 3^{* *}$ & $2 \pm 2^{* *}$ \\
Butyramide & $30 \pm 8 \dagger$ & $17 \pm 9$ & 0 & 0 & 0 \\
\hline
\end{tabular}

The values are mean \pm s.e.m. percentages for 5 determinations. $t$ test).

Significantly different from the value for each isotonic control $(0.31 \mathrm{M}),{ }^{*} P<0.05,{ }^{* *} P<0.01$ (Student's

$\dagger$ Significantly different from the values for the other isotonic controls $(0.31 \mathrm{M}), P<0.05$ (Student's $t$ test).

\section{Sperm survival after freezing and thawing}

Sperm motility after freezing and thawing is shown in Table 2. In the control samples frozen in the diluent without any additive, the post-thawing motility was near zero. Recovery of motility was quite good in samples frozen in the presence of lactamide, dimethylsulphoxide and acetamide and the optimum concentration was $1 \mathrm{M}$. In the other media, except that with dimethylformamide, there was little recovery of motility. Motility was generally reduced with increasing osmolarities. When frozen-thawed semen was rediluted with thawing medium, the motility generally dropped significantly except when acetamide, lactamide, or dimethylformamide were used.

There appeared to be little interaction between concentration of the additive and the reduction in motility on redilution except for semen in the presence of $0.5 \mathrm{M}$-lactamide and $0.75-2 \mathrm{M}$-propionamide for which the interaction was significant.

\section{Fertilizing capacity of frozen-thawed semen}

The results for the first experiment are given in Table 3. The recovery rate of ovulated eggs was $83.9 \%$ and the proportion fertilized was reasonably high except when dimethylformamide 
was used. The cleaved eggs appeared normal, most of them being at the 16-cell stage and with 8-13 spermatozoa attached to the zona pellucida. However, there were very few spermatozoa attached to the surface of the 4 fertilized eggs recovered from the does inseminated with semen frozen in dimethylformamide and no spermatozoa were seen with unfertilized eggs. The proportion of does which gave birth in the second experiment and the litter size are shown in Table 3. There were no significant differences between the groups.

Table 2. Effects of various cryoprotectants in an egg yolk-glucose-lactose-raffinose diluent on the motility of rabbit spermatozoa after pellet freezing and thawing

\begin{tabular}{lrrrrrrrr}
\hline \multicolumn{7}{c}{ Conc. (M) } \\
\cline { 2 - 8 } Cryoprotectant & 0.125 & 0.25 & 0.5 & 0.75 & 1.0 & 1.25 & 1.5 & $2 \cdot 0$ \\
\hline Dimethylsulphoxide & $25 \pm 6$ & $31 \pm 4$ & $31 \pm 6$ & $38 \pm 2$ & $44 \pm 2^{* *}$ & $36 \pm 6$ & $28 \pm 7$ & $17 \pm 6$ \\
Lactamide & $5 \pm 2$ & $5 \pm 2$ & $29 \pm 5$ & $42 \pm 1$ & $53 \pm 4^{* *}$ & - & $47 \pm 4$ & $31 \pm 8$ \\
Acetamide & $9 \pm 4$ & $12 \pm 3$ & $24 \pm 5$ & $37 \pm 2$ & $40 \pm 2^{* *}$ & $33 \pm 7$ & $25 \pm 11$ & $2 \pm 1$ \\
Dimethylformamide & $14 \pm 4$ & $27 \pm 8$ & $32 \pm 6^{* *}$ & $30 \pm 7$ & $19 \pm 6$ & - & - & $-15 \pm 7$ \\
Trimethylene glycol & $19 \pm 6$ & $11 \pm 3$ & $11 \pm 2$ & $13 \pm 4$ & $17 \pm 5$ & $23 \pm 6$ & $16 \pm 8$ & $15 \pm 7$ \\
Ethylene glycol & $12 \pm 5$ & $17 \pm 6$ & $24 \pm 4^{*}$ & $22 \pm 2$ & $22 \pm 2$ & $20 \pm 4$ & $22 \pm 7$ & $15 \pm 6$ \\
Propionamide & $6 \pm 3$ & $4 \pm 1$ & $6 \pm 2$ & $22 \pm 4^{* *}$ & $12 \pm 2$ & $2 \pm 1$ & 0 & 0 \\
Glycerol & $12 \pm 5^{*}$ & $10 \pm 2$ & $8 \pm 1$ & $4 \pm 1$ & $2 \pm 1$ & $<1$ & $<1$ & $<1$ \\
Formamide & $4 \pm 2$ & $6 \pm 2$ & $6 \pm 2$ & $3 \pm 2$ & $<1$ & $<1$ & $<1$ & $<1$ \\
Malomide & $12 \pm 5$ & $5 \pm 2$ & $<1$ & - & - & - & - & - \\
Butyramide & $2 \pm 1$ & 0 & 0 & - & - & - & - & - \\
Without (Control) & $<1$ & & & & & & & \\
\hline
\end{tabular}

Values are mean \pm s.e.m. percentages for 5 determinations.

Highest values in each cryoprotectant group, ${ }^{*} P<0.05,{ }^{* *} P<0.01$ ( $F$ test for variance analysis).

Table 3. Effects of dimethylsulphoxide (DMSO) or amides in an egg yolk-glucose-lactose-raffinose diluent on the fertilizing capacity of rabbit spermatozoa after pellet freezing and thawing

\begin{tabular}{|c|c|c|c|c|c|c|c|}
\hline \multirow[b]{3}{*}{ Cryoprotectant } & \multicolumn{4}{|c|}{ Experiment 1} & \multicolumn{3}{|c|}{ Experiment 2} \\
\hline & \multicolumn{2}{|c|}{ No. of females } & \multicolumn{2}{|c|}{ No. of eggs } & \multicolumn{2}{|c|}{ No. of females } & \multirow[b]{2}{*}{$\begin{array}{l}\text { No. of } \\
\text { young } \\
\text { born } \dagger\end{array}$} \\
\hline & Inseminated & $\begin{array}{c}\text { With } \\
\text { fertilized } \\
\text { eggs }\end{array}$ & Recovered & $\begin{array}{l}\text { Fertilized } \\
(\%)\end{array}$ & Inseminated & $\begin{array}{c}\text { Giving } \\
\text { birth (\%) }\end{array}$ & \\
\hline DMSO (I M) & 5 & 4 & 33 & $26(79)$ & 14 & $13(93)$ & $\begin{array}{c}4 \cdot 7 \pm 2 \cdot 0 \\
(1-8)\end{array}$ \\
\hline Acetamide (1 M) & 6 & 6 & 33 & $29(88)$ & 16 & $14(88)$ & $\begin{array}{c}5 \cdot 1 \pm 2 \cdot 2 \\
(1-8)\end{array}$ \\
\hline Lactamide (1 M) & 5 & 5 & 38 & $26(68)$ & 15 & $11(73)$ & $\begin{array}{c}6 \cdot 1 \pm 1 \cdot 6 \\
(3-8)\end{array}$ \\
\hline $\begin{array}{l}\text { Dimethyl- } \\
\text { formamide } \\
(0.5 \mathrm{M})\end{array}$ & 6 & 2 & 37 & $4(11)^{*}$ & - & - & - \\
\hline
\end{tabular}

* Significantly different from the other values, $P<0.01$ ( $\chi^{2}$ test).

$\dagger$ Mean \pm s.d. and range in parentheses.

\section{Discussion}

Lovelock (1953) proposed that the properties required of an effective cryoprotective agent should be a low molecular weight, an ability to permeate living cells, a high solubility in aqueous electrolyte solutions and be non-toxic. In these ${ }_{1}$ respects, ${ }_{\text {glycerol }}$ has been $_{n}$ outstanding as $_{3} \mathrm{a}_{3: 43 \mathrm{PM}}$ 
cryoprotective agent for the low temperature preservation of spermatozoa of several species. However, good protection against freezing damage of bull spermatozoa during a relatively fast "two-step" cooling process was shown by some sugars, including sucrose which is considered to be impermeable to living cells; the protection provided by sucrose was inferior to that given by some monosaccharides (Polge \& Soltys, 1960). A relatively fast freezing method for bull spermatozoa by pelleting on solid $\mathrm{CO}_{2}$ was developed by Nagase (1962) and Nagase, Niwa, Yamashita \& Irie (1964), and under these conditions it was observed that better protection to cells was provided by di- and trisaccharides than by monosaccharides (Nagase, 1962, 1966; Nagase et al., 1964; Nagase, Yamashita \& Irie, 1968). The pelleting method has been used successfully for preservation of spermatozoa from rams, stallions and boars. It is therefore clear that permeating and non-permeating compounds can be used as cryoprotective agents for spermatozoa. There are, however, marked differences between the spermatozoa of different species in their resistance to freezing and thawing and in the conditions required for their preservation at low temperatures.

Sugars (xylose, raffinose) and polyols (erythritol, sorbitol, inositol) in diluents containing egg yolk appear to give very little protection to rabbit spermatozoa during pellet freezing (Nagase, Hanada \& Tomizuka, 1975) and poor recovery rates have been obtained after freezing rabbit spermatozoa in the presence of glycerol (Smith \& Polge, 1950; present study). The present incubation trials showed that good sperm motility was maintained at $20^{\circ} \mathrm{C}$ in hypertonic solutions of dimethylsulphoxide, trimethylene glycol, acetamide and ethylene glycol, suggesting that these compounds freely permeate the cell membrane of rabbit spermatozoa and are relatively non-toxic. By contrast, sperm survival was low in hypertonic solutions of formamide, propionamide and dimethylformamide. These compounds are of low molecular weight, particularly formamide, and would presumably permeate the cell membrane, so the reduction in sperm motility was probably brought about by their toxicity. On the basis of Lovelock's (1953) proposals, dimethylsulphoxide, trimethylene glycol, ethylene glycol, acetamide and lactamide might all be considered as potentially good cryoprotective agents for rabbit spermatozoa.

The results of the freezing trials supported this theory to some extent because the best recovery rates were obtained with lactamide, dimethylsulphoxide and acetamide. The recovery rates following freezing in media containing ethylene glycol and trimethylene glycol were lower, despite the fact that these substances were able to maintain better motility at high osmolarities than lactamide, acetamide or dimethylsulphoxide in the incubation trials.

Therefore, properties other than high permeability and low toxicity appear also to be required if a solute is to be an effective cryoprotective agent. These results and those cited earlier might suggest that compounds containing hydroxyl groups are relatively less effective cryoprotective agents for rabbit spermatozoa than those containing amide or methyl groups.

The fertility rates obtained with pelleted semen with dimethylsulphoxide, acetamide or lactamide as cryoprotective agents were higher than those reported by O'Shea \& Wales (1969) or by Stranzinger et al. (1971) and were almost equal to those reported by Weitze et al. (1976). Litter size was lower than would be expected from New Zealand White does following natural or artificial insemination with fresh semen, but the techniques described could have useful practical application.

We thank Dr C. Polge (Cambridge) for useful suggestions and help with the manuscript.

\section{References}

Andrieu, R. \& Courot, M. (1976) Deep freezing of rabbit semen for artificial insemination. (Proc. 1st Int. Rabbit Congr., Dijon.) Anim. Breed. Abstr. 46, 54.

Emmens, C.W. (1948) The effect of variations in osmotic pressure and electrolyte concentration on the motility of rabbit spermatozoa at different hydrogen ion concentrations. J. Physiol., Lond. 107, 129140. 
Fox, R.R. \& Burdick, J.F. (1963) Preservation of rabbit spermatozoa, ethylene glycol vs glycerol for frozen semen. Proc. Soc. exp. Biol. Med. 113, 853-856.

Hellemann, C.C. (1977) Motility and acrosome integrity as fertility parameters of deep frozen rabbit semen. (Thesis.) Anim. Breed. Abstr. 45, 635.

Lovelock, J.E. (1953) Biophysical aspects of the freezing of living cells. In The Preservation and Transplantation of Normal Tissues (Ciba Fdn Symp.), pp. 131-138. Eds G. E. W. Wolstenholme \& J. Cameron. Churchill, Edinburgh.

Maurer, R.R., Stranzinger, F.G. \& Paufler, S.K. (1976) Embryonic development in rabbits after insemination with spermatozoa stored at 37,5 or $-196^{\circ} \mathrm{C}$ for various periods. J. Reprod. Fert. 48, 43-49.

Murdoch, B.E. \& O'Shea, T. (1973) Effect of storage of rabbit spermatozoa at $-79^{\circ} \mathrm{C}$ on their subsequent transport and fertility in the rabbit doe. Aust. J. biol. Sci. 26, 645-651.

Nagase, H. (1962) Studies on sperm resistance to deep freezing in domestic animals. III. Cryoprotective effect of different glycerol levels and sugars in the pellet freezing method. Jap. J. Vet. Sci. 24, Suppl. 505. (In Japanese.)

Nagase, H. (1966) Cryoprotective effect of sugars to bull spermatozoa. Jap. J. Anim. Reprod., Suppl. 11, 2-11.

Nagase, H. \& Tomizuka, T. (1969) Studies on the permeability of sperm cell membrane. I. Sperm survival in hypertonic solution of polyols. Jap. $J$. Zootech. Sci. 4, Suppl. 2-3.

Nagase, H., Niwa, T., Yamashita, S. \& Irie, S. (1964) Deep freezing of bull semen in concentrated pellet form. II. Protective action of sugars. Proc. $5 \mathrm{th}$ Int. Congr. Anim. Reprod. \& A. I., Trento 4, 498-502.

Nagase, H., Yamashita, S. \& Irie, S. (1968) Protective effects of sugars against freezing injury to bull spermatozoa. Proc. 6th Int. Congr. Anim. Reprod. \& A. I., Paris 2, 1111-1113.
Nagase, H., Tomizuka, T., Hanada, A., Hosoda, T. \& Morimoto, H. (1972) Cryoprotection of some amide solutes to spermatozoa of domestic animals. I. Effects of formamide, acetamide and lactamide on the motility of bovine spermatozoa in pellet freezing. Jap. J. Anim. Reprod. 18, 15-21. (In Japanese.)

Nagase, H., Hanada, A. \& Tomizuka, T. (1975) Cryoprotective effect of sugars to boar, rabbit and chicken spermatozoa. Jap. J. Zootech. Sci. 46, Suppl. 23. (In Japanese.)

O'Shea, T. \& Wales, R.G. (1969) Further studies on the deep freezing of rabbit spermatozoa in reconstituted skim milk powder. A ust. J. biol. Sci. 22, 709-719.

Polge, C. \& Soltys, M.A. (1960) Protective action of some neutral solutes during the freezing of bull spermatozoa and trypanosomes. In Recent Research in Freezing and Drying, pp. 87-100. Eds A. S. Parkes \& A. U. Smith. Blackwell, Oxford.

Sawada, Y. \& Chang, M.C. (1964) Motility and fertilizing capacity of rabbit spermatozoa after freezing in a medium containing dimethylsulfoxide. Fert. Steril. $15,222-229$.

Smith, A.U. \& Polge, C. (1950) Survival of spermatozoa at low temperature. Nature, Lond. 166, 668-669.

Stranzinger, G.F., Maurer, R.R. \& Paufler, S.K. (1971) Fertility of frozen rabbit semen. J. Reprod. Fert. 24, $111-113$.

Tomizuka, T., Hanada, A., Morimoto, H. \& Nagase, H. (1972) Cryoprotection of some amides to stallion and boar spermatozoa. Jap. J. Zootechn. Sci. 43, Suppl. 48. (In Japanese.)

Wales, R.G. \& White, I.G. (1959) The susceptibility of spermatozoa to temperature shock. J. Endocr. 19, 211.

Weitze, K.F., Hellemann, C. \& Krause, D. (1976) Insemination with rabbit semen frozen in plastic straws. Proc. 8th Int. Congr. Anim. Reprod. \& A. I., Krakow 2, 1100-1103. 